\title{
Suplementos y aditivos en avicultura
}

Ing. Agrop. Leonidas Espinoza

uplementos alimenticios.- Uno de los adelantos más significativos en lo que respecta a la alimentación de los pollos broiler, ha sido el desarrollo de suplementos que contienen enzimas formuladas para mejorar la asimilación de casi cualquier ingrediente de los piensos avícolas.

Las enzimas son sustancias de naturaleza proteica, que actuando en dosis ínfimas, son capaces de catalizar una o varias reacciones de la química metabólica. Es el procedimiento normal por el cual la naturaleza lleva a cabo los procesos de digestión en todo el reino animal.

Cuando determinadas enzimas se añaden ah alimento de las aves, éstas responden con crecimiento más acelerado, mejor calidad de la carne o mejor convertibilidad alimenticia. La incorporación de suplementos enzimáticos a los piensos avícolas, tiene varias razones de peso:

- La suplementación con enzimas simplifica el control de las variaciones en la calidad de los ingredientes, ya que sin importar dichas variaciones, la enzima propicia que todos sean digeridos. Sin la enzima, será necesario un riguroso control de la calidad de los ingredientes, ya que de lo contrario una buena parte de los alimentos no serán siempre bien digeridos, incrementan el valor metabolizado de los ingredientes destinados a proporcionar energía a las aves, ahorrando así alimento,

- Aumentan la digestibilidad de los alimentos, en especial de los proteicos. La asimilación de estos alimentos es también mayor, las aves crecen más rápido, mejoran la convertibilidad y ahorran dinero al avicultor,

- Da lugar a que las fórmulas para los piensos utili- cen ingredientes más baratos, ya que los nutrientes que contienen se metabolizan más eficazmente

- Se aprovecha más eficazmente la energía de grasas y aceites,

- Reducen al mínimo la necesidad de buscar ingredientes fuera de la zona de producción donde se halla instalado el criadero

Otros aditivos.- Junto a los aditivos mencionada arriba, existe una amplia gama de sustancias utilizadas en avicultura moderna para mejorar las condiciones de los alimentos, protegerlos de micro organismos y conseguir efectos especiales en las aves.

Así se tienen productos secuestrantes y destructores de las micotoxinas, (producidas por hongos). Estos aditivos rompen los enlaces químicos de las sustancias nocivas, o tienen capacidad de absorción y retención de las micotoxinas, como es el caso de las arcillas usadas para absorber las aflatoxinas. Otros aditivos son en realidad conservantes alimenticios, para a prevenir la contaminación por hongos de los piensos.

Los Ilamados promotores de crecimiento, son productos comerciales que suelen incluir casi siempre algún tipo de antibiótico, por lo cual su uso debe ser cuidadoso y sujetándose a las instrucciones del fabricante. Se provee también de combinados vitamínicos, llamados también núcleos vitamínicos, así como de minerales (premezclas), que contienen las vitaminas o minerales más importantes para el crecimiento saludable de los pollos broiler.

Por último mencionaremos los colorantes que se añaden a las racionewOpara pigmentar la piel de las aves y hacerla más atractivas para los clientes: Ios hay que son elaborados químicos y los que son extractos de plantas, como es el caso del marigold, un colorante extraído de la planta del mismo nombre, de color amarillo.

El empleo de todos estos aditivos, debería ser supervisado por personal calificado y bajo asesoría de los proveedores y fabricantes. El avicultor que recurra a estos productos, debería además informarse muy bien del efecto de cada sustancia sobre los pollos a las diferentes edades, y de las posibles consecuencias sobre los consumidores de la carne de aves, así como de las repercusiones legales que podría tener el uso de alguno de ellos.

\begin{tabular}{|c|c|c|}
\hline $\begin{array}{l}\text { Nutriente } \\
\text { Proteinas }\end{array}$ & Enzima & $\begin{array}{l}\text { Efecto sobre las aves } \\
\text { - Incremento en la digestibilidad y asimilación de proteinas y de aminoácidos. } \\
\text { - Reducción de nitrógeno en las excresiones. }\end{array}$ \\
\hline Grasas & Lipasa & - Mejor aprovechamiento energético. \\
\hline Fósforo & Fitasa & $\begin{array}{l}\text { - Incremento en la absorción. } \\
\text { - Reducción de fósforo en las excresiones. } \\
\text { - Mejora en la asimilación de cobre, zinc y manganeso. }\end{array}$ \\
\hline$\left(N^{3} S\right)^{*}$ & $\begin{array}{l}\text { Alfa-galactosidasa } \\
\text { Pontosanasa } \\
\text { Beta-glucanasa }\end{array}$ & $\begin{array}{l}\text { - Neutralización de factores antinutritivos. } \\
\text { - Incremento en la utilización de la energía metabolizable. } \\
\text { - Incremento en la digestibilidad de las proteínas. }\end{array}$ \\
\hline $\begin{array}{l}\text { Proteínas, Energía } \\
\text { metabolizable } \\
\text { verdadera, fósforo }\end{array}$ & $\begin{array}{l}\text { Alfa-galactosidasa y } \\
\text { peptidasa conjuntamente }\end{array}$ & $\begin{array}{l}\text { - Incremento en la digestibilidad de las proteínas, energía y fósforo. } \\
\text { - Incremento final de peso, } 2 \% \text {. } \\
\text { - Incremento en consumo de alimento } 0,5 \% \\
\text { - Aumento en la mortalidad } 1,5 \%\end{array}$ \\
\hline
\end{tabular}

